\title{
Decision aid on breast cancer screening reduces attendance rate: results of a large-scale, randomized, controlled study by the DECIDEO group
}

\author{
Aurelie Bourmaud ${ }^{1,2}$, Patricia Soler-Michel ${ }^{3}$, Mathieu Oriol ${ }^{1,4}$, Véronique Regnier ${ }^{1}$, \\ Fabien Tinquaut ${ }^{1}$, Alice Nourissat ${ }^{1}$, Alain Bremond ${ }^{4}$, Nora Moumjid ${ }^{5,6,7}$ and Franck \\ Chauvin ${ }^{1,2,4}$ \\ ${ }^{1}$ Hygée Centre, Lucien Neuwirth Cancer Institut, CIC-EC Inserm 1408, Saint Priest en Jarez, France \\ 2 EMR3738, Therapeutic Targeting in Oncology, Claude Bernard University, Lyon, France \\ ${ }^{3}$ Adémas-69, association pour le dépistage organisé des cancers dans le Rhône, Lyon, France \\ 4 Jean Monnet University, Saint-Etienne, France \\ ${ }^{5}$ Lyon 1 University, Lyon, France \\ ${ }^{6}$ GATE-LSE UMR 5824 CNRS, Lyon, France \\ 7 Léon Bérard Cancer Centre, Lyon, France \\ Correspondence to: Aurélie Bourmaud, email: aurelie.bourmaud@icloire.fr
}

Keywords: breast cancer screening, decision aid, informed decision, decision making patient education, randomized control trial Received: October 30, 2015

Accepted: January 27, 2016

Published: February 11, 2016

\section{SUMMARY}

Controversies regarding the benefits of breast cancer screening programs have led to the promotion of new strategies taking into account individual preferences, such as decision aid. The aim of this study was to assess the impact of a decision aid leaflet on the participation of women invited to participate in a national breast cancer screening program. This Randomized, multicentre, controlled trial. Women aged $\mathbf{5 0}$ to $\mathbf{7 4}$ years, were randomly assigned to receive either a decision aid or the usual invitation letter. Primary outcome was the participation rate 12 months after the invitation. 16000 women were randomized and 15844 included in the modified intention-to-treat analysis. The participation rate in the intervention group was $40.25 \%$ (3174/7885 women) compared with $42.13 \%$ (3353/7959) in the control group $(p=0.02)$. Previous attendance for screening (RR = 6.24; [95\%IC: 5.75-6.77]; $p<0.0001)$ and medium household income (RR = 1.05; [95\%IC: 1.01-1.09]; $p=$ 0.0074 ) were independently associated with attendance for screening. This largescale study demonstrates that the decision aid reduced the participation rate. The decision aid activate the decision making process of women toward non-attendance to screening. These results show the importance of promoting informed patient choices, especially when those choices cannot be anticipated.

\section{INTRODUCTION}

Breast cancer is the second most common cancer worldwide and remains the leading cause of cancer death among women [1]. During the last three decades, collective efforts have been made to improve early diagnosis of breast cancer with the aim of decreasing its burden. Breast cancer screening programs have been implemented in numerous countries, mainly as organized population-based breast cancer screening programs [2-
6]. The modalities of population-based breast cancer screening vary between countries, but they mainly involved women aged between 50 and 69, with a twoview mammography screening every two years $[4,7,8]$. Although countries aim to achieve $100 \%$ participation they actually reach a rate of $50 \%$ to $80 \%$ [9].

Benefits in terms of mortality reduction are not clearly documented [10-13]. It has been suggested that prevention campaigns should change from persuasive approaches to approaches based on information and 
women's decision empowerment [14-17].

Decision aids could inform women about the different options available and increase awareness of the benefits and harms associated with breast cancer screening. This would lead women to express their preferences in an informed decision-making process $[18,19]$. The development of tools to increase patient empowerment has been strongly endorsed by several organizations in France and elsewhere [20-22].

Although several decision aids are available for breast cancer screening, only a few of them have been properly evaluated and implemented using validated methods [18, 23, 24].

A decision aid, known as the DECIDEO leaflet, was developed following international guidelines for the 'provision of information and the construction of decision aid tools' $[25,26]$. This tool is a 12-page pocket leaflet presenting the different health decision options and providing probabilities of the outcomes according to the choices made, highlighted by illustrations and histograms [25]. Our hypothesis was that this decision aid would increase informed choice in the intervention group. We estimated the effect of this written decision aid on informed choice, by measuring the participation rate of a population-based breast cancer screening. A randomized, controlled trial in a large sample of French women who were invited to participate in a population-based breast cancer screening program was conducted.

\section{RESULTS}

\section{Study population}

Among the 1104000 estimated women aged between 50 and 74, registered with the French Health Insurance System of the 11 study departments, 16000 women were randomized to participate in this study and then randomly assigned to the decision aid group or to the standard information group (in each group $N=8000$ Figure 1; e-table 1). A total of 156 women were excluded from the analyses because they had had a mammography within the week before randomization (41 in the control group vs. 115 in decision aid group). We collected information about breast cancer screening attendance during the 12 months that followed the expedition of the invitations. The baseline characteristics were comparable between the two groups (Table 1).

\section{Outcomes}

A total of 3174 women in the decision aid group and for 3353 women in the control group attended breast cancer screening in the 12 months following the invitation. The overall participation rate at 12 months (Table 2), was significantly higher in the control group: $42.13 \%$ versus $40.25 \%$ in the decision aid group ( $p=0.02$ ).

Women in the decision aid group attended the screening earlier (following their invitation) than those in the control group (2.8 months compared with 3 months,

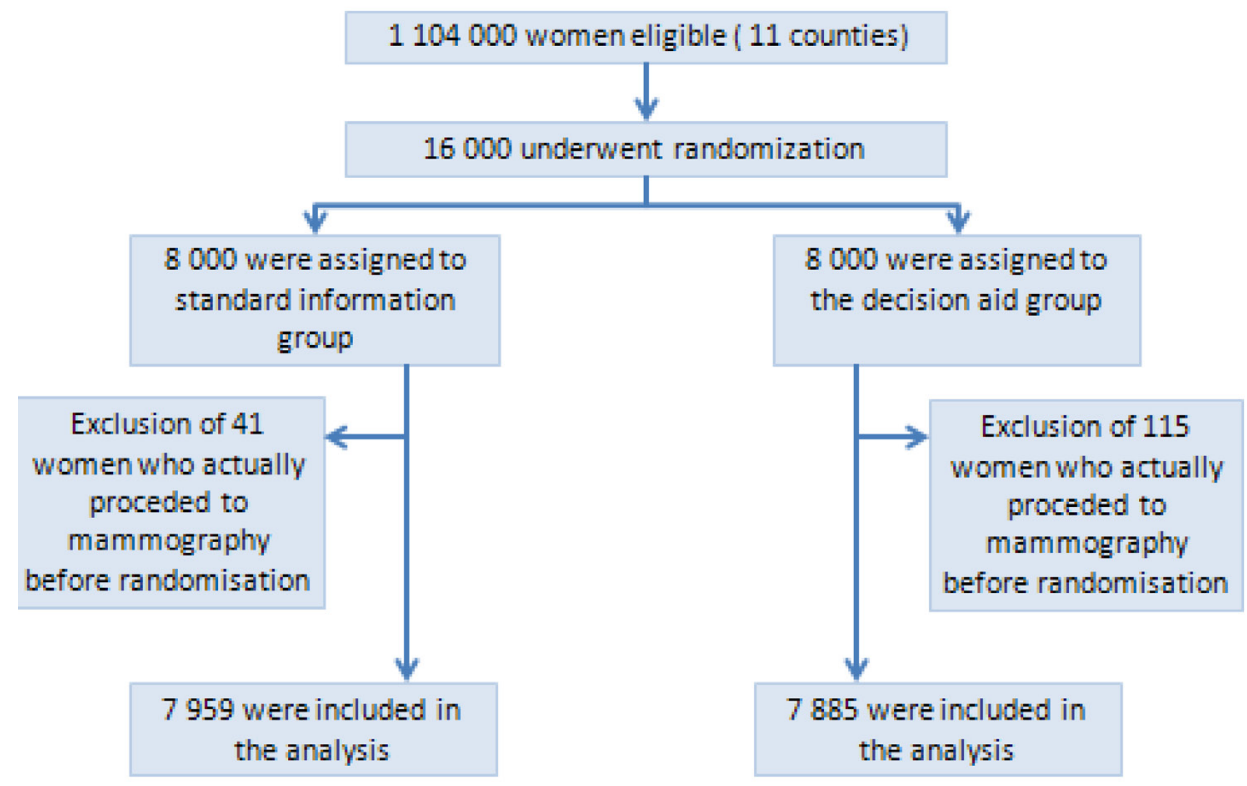

Figure 1: Randomization and follow-up of study participants. Some women were excluded because there was a delay between the invitation being sent by the cancer screening association and its reception by the women; during the delay some of the randomized women had already attended breast cancer screening since they did not need to take the invitation letter with them. 
respectively, $p=0.0025)$. The cumulative rates of breast cancer screening attendance in each group are shown in eFigure 1. The results from the post-hoc analyses showed that there was a heterogeneous effect of the decision aid (Figure 2). In particular, women living in two departments (Loire and Haute Loire, $p<0.0001$ ) or with lower estimated household income $(p=0.03)$ had a lower rate of screening attendance when randomized in the intervention group. The results from the logistic regression analyses showed that being in the intervention group $(\mathrm{OR}=0.86 ; 95 \% \mathrm{CI}[0.79-0.94] p=0.0008)$, having previously attended breast cancer screening $(\mathrm{OR}=15.7$; 95\%CI [14.2-17.4] $p<0.0001)$ and having an estimated household income of between 25000 and 35000 euros $(\mathrm{OR}=1.13 ; 95 \% \mathrm{CI}[1.03-1.2] p=0.01)$ were independent factors associated with women's attendance for breast cancer screening (Table 3). The results for the HosmerLemeshow goodness of fit test was not significant ( $p=$ 0.91 ) and the C-statistic, 0.78 , for the area under the curve (AUC) was acceptable.

\section{DISCUSSION}

This is the fourth study to assess a decision aid for breast cancer screening. Yet it is the first to compare a decision aid for women covered by organised breast cancer screening (aged 50-74), versus the usual practice; the first in Europe, and the first with such a large sample [27-29] . Our results demonstrate that a decision aid, designed following specific guidelines, sent with a formal invitation to attend breast cancer screening, resulted in a lower attendance rate and a decrease in the delay of attendance for the women who did participate.

The main result of this study was a decrease in attendance to the national screening in women involved into an informed decision process when compared with the control group. Additionally, we found evidence of geographical heterogeneity for the effect of the intervention, with a major attendance reduction in two departments. Results from our post-hoc analyses suggest that the DECIDEO leaflet discouraged older women, as well as those with a low mean household income, from attending the national breast cancer screening program. It is known that information about potential harm, may dissuade those from lower-level education groups from taking on preventive health behavior, compared with higher-level education groups. The information provided emphasizes the immediacy of the negative consequences and the devaluation of the future benefits of prevention [30]. Additionally, the decision aid was tested with urban women, probably having a high educational level. Women with a lower educational level could have had difficulty in understanding the decision aid. Those two phenomena could partly explain the effect of the DECIDEO leaflet on those specific populations, additional studies being needed to confirm this hypothesis.

To the best of our knowledge, only two randomized trials previously assessed the effect of a decision aid

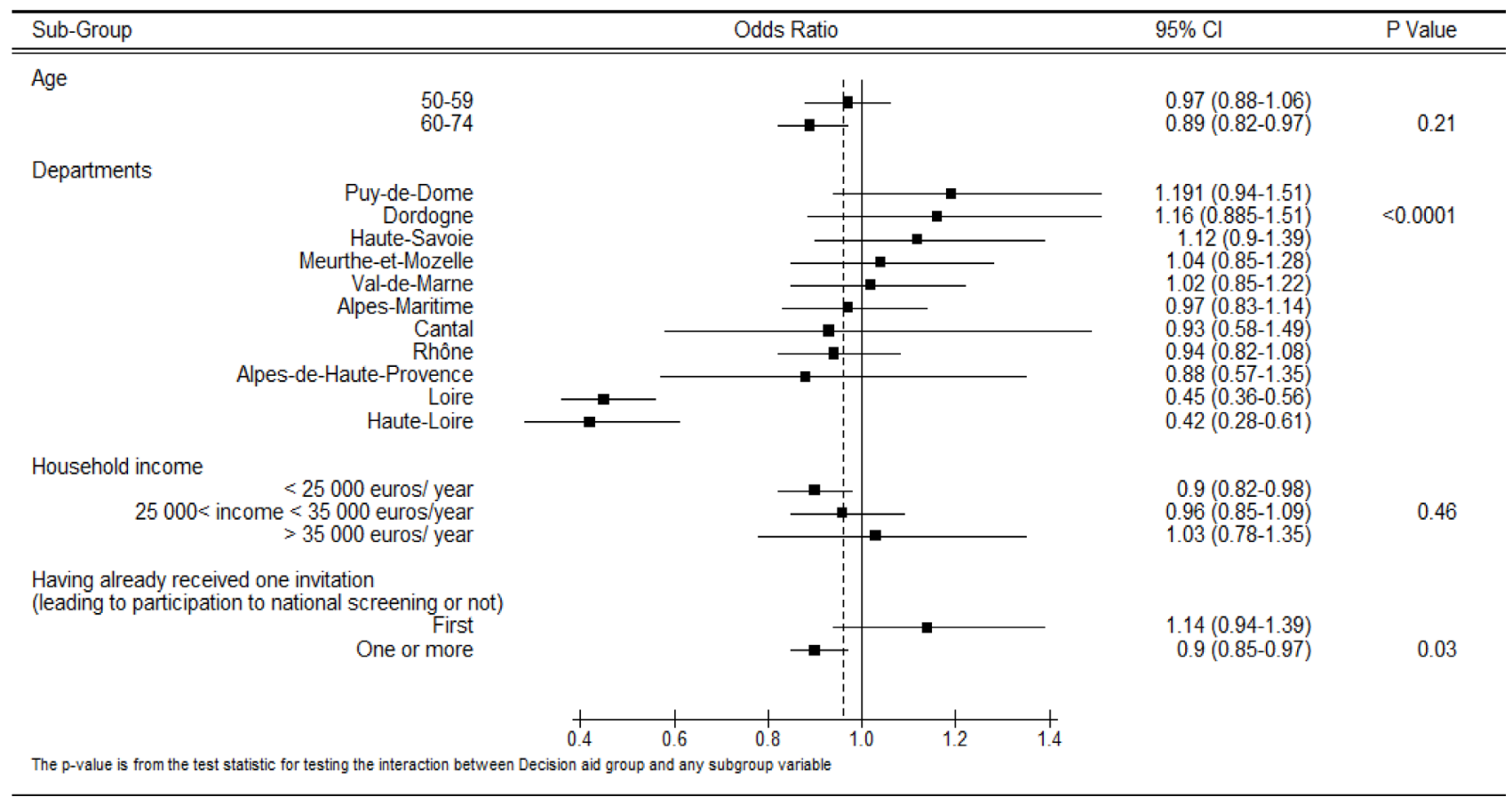

Figure 2: Sub-group analyses to identify baseline characteristics associated with breast cancer screening attendance. Results are reported as odds ratios with $95 \%$ confidence intervals (CI) (horizontal bar). The dotted vertical line represents the odds ratio in the whole sample (odds ratio $0.86,95 \% \mathrm{CI}: 0.79-0.94, P=0.0008$ ). 
Table 1: Baseline characteristics of participants $(N=15844)$ by study group: decision aid (intervention) and standard information (control group)

\begin{tabular}{|c|c|c|c|}
\hline Characteristics & $\begin{array}{l}\text { Decision aid } \\
N=7885 \\
N(\%) \\
\end{array}$ & $\begin{array}{l}\text { Standard information } \\
N=7959 \\
N(\%) \\
\end{array}$ & $P$ value \\
\hline \multicolumn{4}{|l|}{ Age (years) } \\
\hline $50-59$ & $3716(47.1)$ & $3830(48.1)$ & \\
\hline $60-74$ & $4169(52.9)$ & $4129(51.9)$ & 0.21 \\
\hline \multicolumn{4}{|c|}{\begin{tabular}{l|l} 
Number of invitations already received (leading & \\
to participation to national screening or not): & \\
\end{tabular}} \\
\hline First & $873(11.1)$ & $824(10.4)$ & \\
\hline One or more & $7005(88.9)$ & $7128(89.6)$ & 0.14 \\
\hline \multicolumn{4}{|l|}{ Previous screening attendance } \\
\hline Yes & $3570(45.3)$ & $3746(47.1)$ & \\
\hline No & $3428(43.5)$ & $3462(43.5)$ & 0.25 \\
\hline Not applicable & $887(11.3)$ & $751(9.4)$ & \\
\hline \multicolumn{4}{|l|}{ Household income } \\
\hline$<25000$ euros/ year & $4394(64.4)$ & $4415(64)$ & \\
\hline $25000-35000$ euros/year & $1990(29.2)$ & 2065 (29.9) & 0.48 \\
\hline$>35000$ euros/ year & $443(6.5)$ & $423(6.1)$ & \\
\hline \multicolumn{4}{|l|}{ Geographical origin } \\
\hline Urban county & $6871(87.1)$ & $6880(86.4)$ & \\
\hline Rural county & $1014(12.9)$ & $1079(13.6)$ & 0.20 \\
\hline
\end{tabular}

Table 2: Attendance and delay for breast cancer screening by study group [n (\%) or median (IQR)]

\begin{tabular}{|l|l|l|l|}
\hline Outcome & $\begin{array}{l}\text { Decision Aid } \\
(\mathbf{N = 7 8 8 5})\end{array}$ & $\begin{array}{l}\text { Standard information } \\
(\boldsymbol{N = 7 9 5 9 )}\end{array}$ & $\boldsymbol{P}$ value \\
\hline $\begin{array}{l}\text { Attendance at breast screening within } 12 \\
\text { months }\end{array}$ & $3174(40 \%)$ & $3353(42 \%)$ & 0.02 \\
\hline Delay to attendance (months) & $2.8(1.3-4.9)$ & $3(1.5-5.1)$ & $0.0025^{\mu}$ \\
\hline
\end{tabular}

${ }^{\mu}$ Wilcoxon test was used since delay was not normally distributed

Table 3: Independent factors associated with women's attendance to breast screening

\begin{tabular}{|c|c|c|c|c|c|c|}
\hline \multirow{2}{*}{ Characteristics } & \multicolumn{2}{|c|}{ Univariate analysis } & \multirow[b]{2}{*}{$p$ value } & \multicolumn{2}{|l|}{ Multivariate analysis } & \multirow[b]{2}{*}{$p$ value } \\
\hline & Odds ratio & $95 \% \mathrm{CI}$ & & Ajusted Odds Ratio & $95 \% \mathrm{CI}$ & \\
\hline Decision aid group & 0.91 & {$[0.84-0.97]$} & 0.007 & 0.86 & {$[0.79-0.94]$} & 0.0008 \\
\hline Age in year & & & & & & \\
\hline $50-59$ & 1 & - & & & & \\
\hline $60-74$ & 1.02 & {$[0.95-1.1]$} & 0.58 & & & \\
\hline $\begin{array}{l}\text { Number of invitations } \\
\text { already received (leading } \\
\text { to participation to national } \\
\text { screening or not) }{ }^{\mu} \\
\text { First }\end{array}$ & 1 & - & & & & \\
\hline One or More & 1.30 & {$[1.02-1.66]$} & 0.03 & & & \\
\hline $\begin{array}{l}\text { Previous attendance at } \\
\text { breast cancer screening } \\
\text { Household income }\end{array}$ & 15.8 & {$[14.2-17.4]$} & $<0.0001$ & 15.7 & {$[14.2-17.4]$} & $<0.0001$ \\
\hline$<25000$ euros/ year & 1 & - & & 1 & - & \\
\hline 25000 - 35000 euros/year & 1.26 & {$[1.17-1.37]$} & $<0.0001$ & 1.13 & {$[1.03-1.2]$} & 0.01 \\
\hline$>35000$ euros/ year & 1.03 & {$[0.89-1.20]$} & 0.67 & 1.02 & {$[0.85-1.2]$} & 0.86 \\
\hline
\end{tabular}


on attendance for breast cancer screening [27, 29]. The Mathieu et al. [27] trial focusing in 70-year-old women found no effect of the decision aid device as regard to the attendance rate. As for Hersch et al [29], they compared two decision aids for screening attendance, with two different internal messages. The scientific question addressed by Hersch was then different to ours: he assessed the effect of information about overdiagnosis on women.

This study is the first to compare a decision aid to real life: the control group consisted of women aged 50 to 74 , receiving the usual information about screening. Our results are however in accordance with previous trials in this field suggesting a decreased attendance as results of the implementation of a decision aid on cancer screening [18].

Our study had several limitations. First, we decided not to collect variables assessing decision making process such as knowledge, anxiety, decisional conflict and preferences. However, assessing only the effect of the decision allowed us to eliminate the Hawthorne effect (the women did not know they were being studied). Additionally, the shorter delay for screening attendance for the women in the decision aid group suggests an activation of the decision process by the decision aid, confirmed by the dynamics of screening attendance over time (eFigure 1). Another limitation is that the recent data about overdiagnosis and overtreatment has not been implemented in the decision aid. However, this information is likely to decrease the attendance to screening and might have only amplified the effect of the decision aid in our study. Another limitation of our study is the heterogeneity observed in the subgroup analyses results. Some of this heterogeneity can be explained by the differences in mean annual income, but some variations remain unexplained. Factors, such as competing priorities (budget, employment, children scholarship or other health issues), that may have influenced the decision-making process, were not explored. One last limitation concerns the imbalance in the number of women excluded from the analysis due to screening attendance before reception of the invitation (115 vs 41 in the intervention and control groups, respectively).

\section{CONCLUSIONS}

In this large, randomized, clinical trial we observed that the DECIDEO decision aid resulted in decreased breast cancer screening attendance although it accelerated the decision to attend, for those women who did attend. These results suggest that this leaflet have accomplished its main purpose which was to inform the decision-making process.

We believe that our results highlight the dilemma between the goals of population health initiatives and individual choices. However, in the current climate that increasingly favors a balanced, honest presentation of the benefits and harms of screening, it seems important to promote tools for improving informed patient choices.

\section{MATERIALS AND METHODS}

\section{Trial design}

This was a multicenter, controlled trial in which women, who were expecting to receive an invitation for the French national breast cancer screening, were randomized to receive either a decision aid sent with the invitation or the usual standard invitation.

\section{Complete methods are detailed in e-appendix}

\section{Participants and recruitment}

Women, aged between 50 and 74, living in 11 French departments and scheduled to be invited to national screening between May and June 2009 were screened and randomized. Women who had already been diagnosed with cancer, were excluded.

\section{Randomization}

Women aged between 50 and 74 and registered with the French Health Insurance System in the 11 departments were randomly selected through a list-based sample to participate in the study. Women were randomly assigned in a 1:1 ratio via computer-generated, centralized randomization sequence, to the DECIDEO or usual invitation group. The randomization was balanced through stratification according to the following hierarchy: the department, the age, and the number of invitations already received by the woman.

The study was approved by an institutional review board (Ethical Committee of Saint Etienne University Hospital ( $\mathrm{N}^{\circ}$ IORG004981), December $\left.4^{\text {th }} 2008\right)$ which waived the need for signed and informed consent according to French law.

\section{Interventions}

\section{Decision aid group}

Women allocated to the decision aid group received an invitation to participate in the national breast cancer screening program as well as the specially-designed decision aid (a leaflet), by mail. The paper-based leaflet DECIDEO is a 12-page pocket leaflet providing scientific 
information about the advantages and disadvantages of participating in the national breast screening program, understandable by all, created to conform with the International Patient Decision Aid Standards [25, 26] (a complete decision aid is retrievable in e-appendix) .

\section{Control group}

Women in the control group received an invitation and the usual standard information leaflet, by mail. This invitation is an administrative letter sent to women scheduled to be invited to participate in the national screening program every two years from the age of 50 onwards.

\section{Outcome measures}

Twelve months after the invitations were sent, the participation status of the randomized women was collected, as well as the date of attendance.

\section{Primary outcome}

The primary outcome was the women's attendance rate for the breast cancer screening program during the 12 months following the invitation.

\section{Secondary outcome}

The secondary outcome was the delay between the invitation and the date of attendance for breast cancer screening. In addition, the demographic details and other characteristics of the women were collected.

\section{Sample size}

The study sample size was calculated with an assumption of a $50 \%$ attendance rate (which was the mean participation rate observed in the 11 participating departments, in 2007). We estimated that there would be a $3 \%$ modification in the attendance rate (a $6 \%$ relative modification). With an alpha risk of $5 \%$ and a beta risk of $95 \%$, we calculated that we needed to include 7209 women in each group for a bilateral test (since a positive or a deleterious effect of the intervention could equally be possible). To take into account the lost to follow-up and the risk of contamination bias, we increased the group size by $10 \%$, giving a sample size of 8000 women in each group.

\section{Statistical analysis}

The results were analyzed using a modified intention-to-treat population. The statistical analyses were performed with a Pearson's Chi Square test (Fisher exact test if statistical conditions were not satisfied) for ordinal variables or a Student's T test ( Wilcoxon test if statistical conditions were not satisfied) for continuous variables . Variables that were significantly associated with attendance in univariate analyses $(p$. value $<0.05)$ were introduced in a stepwise manner in a multivariate logistic regression model to identify independent predictive factors (exit $p$.value $<0.05$ ). We also compared the primary outcome in post-hoc defined subgroups to identify potential heterogeneous behavior. All p-values are two sided, with the threshold of significance set at $p<$ 0.05. All analyses were carried out using SAS version 9.3.

This study was later registered in clinicaltrial.gov on 03/19/2014, since the principal outcome was a screening attendance rate, therefore not considered as a "health outcome" by the steering committee and the local IRB. Thus, this was considered as off the range, according to the ICMJE definition of a clinical trial at the time of study initiation.

This study was supported by the French National Association against Cancer (Ligue National Contre le Cancer). This organization was not involved, at any time, in the design and conduct of the study.

\section{ACKNOWLEDGMENTS}

\section{Authors contributions}

ABo had full access to all the data in the study and takes responsibility for the integrity of the data and the accuracy of the data analysis.

$\mathrm{ABr}, \mathrm{PSM}$ and NM conceived the project. FC and $\mathrm{ABo}$ coordinated the study. ABo collected the data. MO and FT performed the statistical analyses. $\mathrm{ABo}$ and $\mathrm{MO}$ wrote the first draft and revised drafts of the manuscript. FC, ABr, PSM, NM and FT critically revised the manuscript for important intellectual content. All authors had full access to all the study data and can take responsibility for the integrity of the data. The final version of the manuscript was approved by all the authors.

\section{Ethical approval}

The ethical committee of Saint Etienne University Hospital approved this study.

\section{Additional contributions}

The authors would like to thank the directors of all the cancer screening associations who participated in the whole study: Laurent Bailly (APREMAS), François Bordes (VITALIS), Zahida Brixi (ADOC 94), Alain Isnard (ARDOC), Janine Kuntz Huon (VIVRE !), Catherine Morel (ADECA 54), André Peccoud (Réseau pour le dépistage des cancers en Haute-Savoie).

The authors would like to thank Elisabeth Gormand 
for her contribution to the construction of the DECIDEO leaflet.

The authors would also like to thank Margaret Haugh (MediCom Consult) and Susan Guillaumond for translation and editing services, funded by the Hygée Centre (Institut de Cancérologie Lucien Neuwirth, Saint Etienne, France).

\section{FUNDING/SUPPORT AND ROLE OF SPONSOR}

This study was supported by the French National Association against Cancer (Ligue National Contre le Cancer). This organization was not involved in the design and conduct of the study, at any time.

\section{CONFLICTS OF INTEREST}

PSM declares a conflict of interest through her activity, being a practionner involved in breast cancer screening promotion at a local level. All the others authors declare no financial support for the submitted work; no relationships that might have an interest in the submitted work in the previous three years; None of their spouses, partners, or children have financial relationships that may be relevant to the submitted work; and none have nonfinancial interests that may be relevant to the submitted work.

\section{Editorial note}

This paper has been accepted based in part on peerreview conducted by another journal and the authors' response and revisions as well as expedited peer-review in Oncotarget.

\section{REFERENCES}

1. Bray F, Ren J-S, Masuyer E, Ferlay J. Global estimates of cancer prevalence for 27 sites in the adult population in 2008. International Journal of Cancer. 2013; 132:1133-45.

2. Nelson HD, Tyne K, Naik A, Bougatsos C, Chan BK, Humphrey L, U.S. Preventive Services Task Force. Screening for breast cancer: an update for the U.S. Preventive Services Task Force. Ann Intern Med. 2009; 151:727-737, W237-242.

3. Care TCTF on PH. Recommendations on screening for breast cancer in average-risk women aged 40-74 years. CMAJ. 2011; 183:1991-2001.

4. Agence Nationale d'Acreditation et d'Evaluation en Sante. Le depistage du cancer du sein par mammographie dans la population generale. Etude d'evaluation technologique. Paris: ANAES; 1999.

5. Olsson S, Andersson I, Karlberg I, Bjurstam N, Frodis E,
Håkansson S. Implementation of service screening with mammography in Sweden: from pilot study to nationwide programme. J Med Screen. 2000; 7:14-8.

6. Australian Institute of Health and Welfare. BreastScreen Australia Monitoring Report 2009-2010. AIHW; 2012. 95 p.

7. Autier P, Koechlin A, Smans M, Vatten L, Boniol M. Mammography screening and breast cancer mortality in Sweden. J Natl Cancer Inst. 2012; 104:1080-93.

8. Heidinger O, Batzler WU, Krieg V, Weigel S, Biesheuvel C, Heindel W, Hense HW. The incidence of interval cancers in the German mammography screening program: results from the population-based cancer registry in North RhineWestphalia. Dtsch Arztebl Int. 2012; 109:781-7.

9. Autier P, Boniol M, Gavin A, Vatten LJ. Breast cancer mortality in neighbouring European countries with different levels of screening but similar access to treatment: trend analysis of WHO mortality database. BMJ. 2011; 343:d4411.

10. Vannier MW. Screening mammography: what good is it and how can we know if it works? J Natl Cancer Inst. 2012; 104:1039-40.

11. Independent UK Panel on Breast Cancer Screening. The benefits and harms of breast cancer screening: an independent review. Lancet. 2012; 380:1778-86.

12. Marmot MG, Altman DG, Cameron DA, Dewar JA, Thompson SG, Wilcox M. The benefits and harms of breast cancer screening: an independent review. Br J Cancer. 2013; 108:2205-40.

13. O'Donoghue C, Esserman L. Recognising the benefits and harms of breast cancer screening: an opportunity to target improvement. Br J Cancer. 2013; 108:2200-1.

14. Woloshin S, Schwartz LM, Black WC, Kramer BS. Cancer screening campaigns - getting past uninformative persuasion. N Engl J Med. 2012; 367:1677-9.

15. Walter LC, Lewis CL. Maximizing informed cancer screening decisions. Arch Intern Med. 2007; 167:2027-8.

16. Patient empowerment-who empowers whom? Lancet. 2012; 379:1677.

17. Raffle AE. Informed participation in screening is essential. BMJ. 1997; 314(7096):1762-3.

18. Stacey D, Légaré F, Col NF, Bennett CL, Barry MJ, Eden KB, Holmes-Rovner M, Llewellyn-Thomas H, Lyddiatt A, Thomson R, Trevena L, Wu JH. Decision aids for people facing health treatment or screening decisions. Cochrane Database Syst Rev. 2014; 1:CD001431.

19. Barratt AL. Breast screening overdiagnosis. Consensus and decision aids. BMJ. 2009; 339:b3260.

20. Goldsmith M, Bankhead C, Austoker J, NHS Cancer Screening Programmes, National Breast Screening Programme (Great Britain). Improving the quality of the written information sent to women about breast screening: guidelines on the content of letters and leaflets. Sheffield: NHS Cancer Screening Programmes; 2007. 
21. Agency for Healthcare Research and Quality. health IT tools and resources. Health information technology. Available from: http://healthit.ahrq.gov/health-it-tools-and-resources

22. Haute Autrorité de Santé. Patient et professionnels de santé : décider ensemble - Concepts, aides destinées aux patients et impact de la "décision médicale partagée". Etat des lieux. HAS; 2013 Oct. Report No.: 978-2-11-1380646. Available from: http://www.has-sante.fr/portail/upload/ docs/application/pdf/2013-10/12iex04_decision_medicale_ partagee_mel_vd.pdf

23. Stacey D, Samant R, Bennett C. Decision making in oncology: a review of patient decision aids to support patient participation. CA Cancer J Clin. 2008; 58:293-304.

24. Barratt A, Trevena L, Davey HM, McCaffery K. Use of decision aids to support informed choices about screening. BMJ. 2004; 329:507-10.

25. Elwyn G, O’Connor A, Stacey D, Volk R, Edwards A, Coulter A, Thomson R, Barratt A, Barry M, Bernstein S, Butow P, Clarke A, Entwistle V, et al. Developing a quality criteria framework for patient decision aids: online international Delphi consensus process. BMJ. 2006; $333: 417$.

26. IPDAS Collaboration. International Patient Decision Aids Standards (IPDAS) Collaboration. 2013. Available from: http://ipdas.ohri.ca

27. Mathieu E, Barratt A, Davey HM, McGeechan K, Howard $\mathrm{K}$, Houssami N. Informed choice in mammography screening: a randomized trial of a decision aid for 70-yearold women. Arch Intern Med. 2007; 167:2039-46.

28. Mathieu E, Barratt AL, McGeechan K, Davey HM, Howard K, Houssami N. Helping women make choices about mammography screening: an online randomized trial of a decision aid for 40-year-old women. Patient Educ Couns. 2010; 81:63-72.

29. Hersch J, Barratt A, Jansen J, Irwig L, McGeechan K, Jacklyn G, Thornton H, Dhillon H, Houssami N, McCaffery K. Use of a decision aid including information on overdetection to support informed choice about breast cancer screening: a randomised controlled trial. Lancet. 2015; 385:1642-52.

30. Crockett R, Wilkinson TM, Marteau TM. Social patterning of screening uptake and the impact of facilitating informed choices: psychological and ethical analyses. Health Care Anal. 2008; 16:17-30. 